\title{
PYLORIC STENOSIS IN ADULTS
}

\author{
C. T. Howe, B.M., B.CH. \\ Research Assistant, Department of Surgical Studies \\ M. P. SPENCE, M.B., B.ChiR., M.R.C.P. \\ Senior Medical Registrar \\ Middlesex Hospital, London, W.I
}

Pyloric stenosis is defined as an obstruction to gastric emptying due to any cause situated above the biliary ampulla. This article is concerned with the clinical features, metabolic disorder, assessment and treatment of patients with pyloric stenosis; anatomical narrowing of the pyloric canal without delay in gastric emptying is not considered. In adults, symptoms due to the underlying lesion may precede by weeks, months or years those due to obstruction and contribute to the clinical picture to a varying degree. Pyloric stenosis is unique among gastro-intestinal disorders which produce electrolyte disturbances in the constancy with which it causes extracellular alkalosis and it is this aspect of the condition that has received most attention in recent years.

\section{Clinical Features}

Benign peptic ulceration is the commonest cause of pyloric stenosis and was responsible for $86 \%$ of 1 I 8 cases reviewed by Balint and Spence. ${ }^{1}$ In $80 \%$ the ulcer was situated at or near the pylorus, but in $6 \%$ there was a remote gastric ulcer with surrounding inflammatory and fibrous tissue which shortened the lesser curve and extended to envelop the pylorus. Carcinoma of the pyloric region accounted for $1 \mathrm{I} \%$ of the cases in this series. Uncommon causes are cholecystitis with involvement of the pylorus in adjacent inflammatory tissue and carcinoma of the pancreas or duodenum. Rarely patients present in adult life with congenital conditions such as hypertrophic pyloric stenosis, duodenal diaphragmatic occlusion or compression of the pylorus by cholecysto-jejunal bands.

Earlier surgical treatment has reduced the number of peptic ulcers that progress to pyloric stenosis. It has been estimated to arise in about $3 \%$ of patients with duodenal ulcers (including pyloric and pre-pyloric ulcers), and in $1 \%$ of those with lesser curve ulcers.

Benign duodenal ulceration causes cicatricial narrowing of the pylorus, but in almost all cases of pyloric stenosis distortion by inflammatory oedema is the precipitating cause of obstruction. This is why pre-operative preparation commonly results in relief of both pain and gastric retention. It is exceptional to find a healed ulcer in a patient with unrelieved pyloric stenosis.

Vomiting is the cardinal symptom and is rarely absent. Usually it is preceded by a long history of recurrent dyspepsia and is sometimes episodic, the episodes coinciding with active phases of the ulcer. In half the patients the vomit is copious, usually free from bile and may contain undigested (and recognizable) food taken many hours before. Typically the vomiting occurs in the late hours of the evening or in the early hours of the morning. Anorexia and weight loss are the rule. Diarrhoea occurs more frequently ( $20 \%$ of cases) than might be expected in an obstructive lesion of the upper alimentary tract. Offensive eructation is a diagnostically helpful symptom when it occurs.

In approximately half the patients in whom pyloric stenosis is diagnosed there are no abnormal physical signs. A gastric succussion splash, only significant if at least three hours have elapsed since the last meal, is the commonest abnormal finding. Visible waves of gastric peristalsis coursing across the abdomen from left to right are of great diagnostic value, and occasionally it is possible to see the outline of a grossly distended stomach. Signs of fluid depletion or latent tetany may be found. Gastric aspiration is the most valuable single diagnostic procedure. The normal stomach is empty three to four hours after a meal, but this time may be prolonged by such factors as emotion, a fatty meal, or an attack of migraine. Nevertheless, the repeated presence of a large gastric residue, i.e. more than $250 \mathrm{ml}$. in patients on a normal hospital diet, four or more hours after the last meal, is an almost certain indication of pyloric stenosis.

Barium-meal examination usually reveals pyloric 


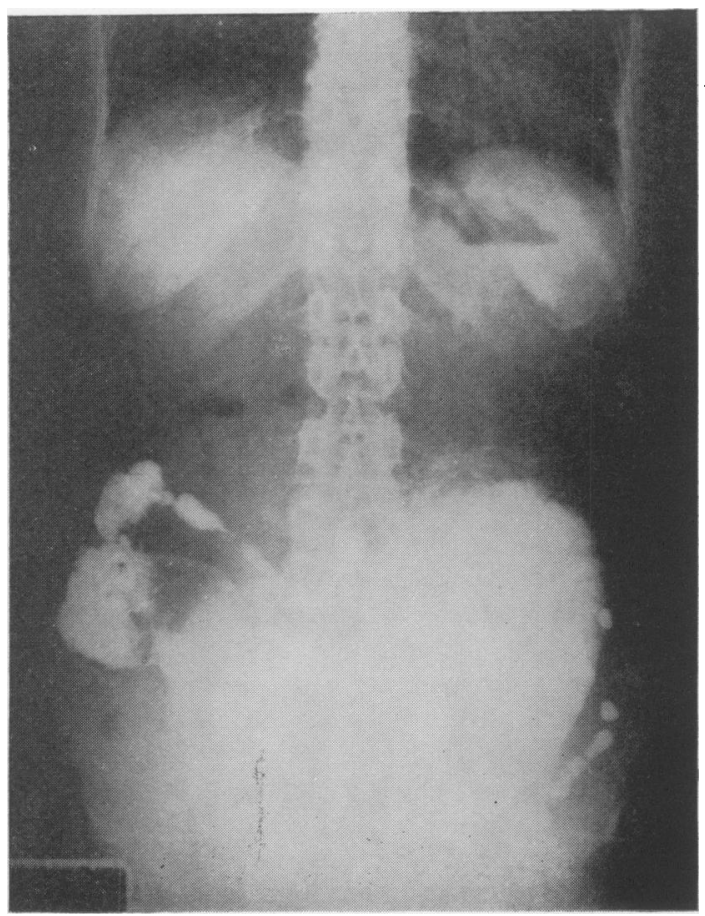

FIG. I.- Radiograph of the abdomen of a patient with pyloric stenosis one week after a barium meal. The whole lower abdomen is filled by a grossly distended stomach still containing a large barium residue.

stenosis when it is present and is of additional value in determining the underlying lesion. Preliminary fluoroscopy may show a dilated stomach and it is wise to empty this by aspiration before giving barium, otherwise it may be impossible to demonstrate the cause of the stenosis. Obstruction may be intermittent in the early stages and cannot be excluded by the demonstration of normal emptying at one examination. A word of caution is necessary about barium-meal examination in suspected cases. In severe pyloric obstruction, barium, like food residues, may remain in the stomach for many days, presenting a major obstacle to the proper preparation and treatment of the patient (Figs. I and 2).

Usually the diagnosis of pyloric stenosis is easy, but it may remain unsuspected if the vomiting is mistakenly ascribed to uncomplicated peptic ulceration. The vomitus may resemble that of exsanguinating haematemesis and diagnosis may be extremely difficult particularly as the conditions may co-exist. Significant blood loss even in the presence of pyloric obstruction is usually accompanied by melaena. If abdominal pain is severe its association with vomiting may mimic an acute surgical emergency. Diarrheoa

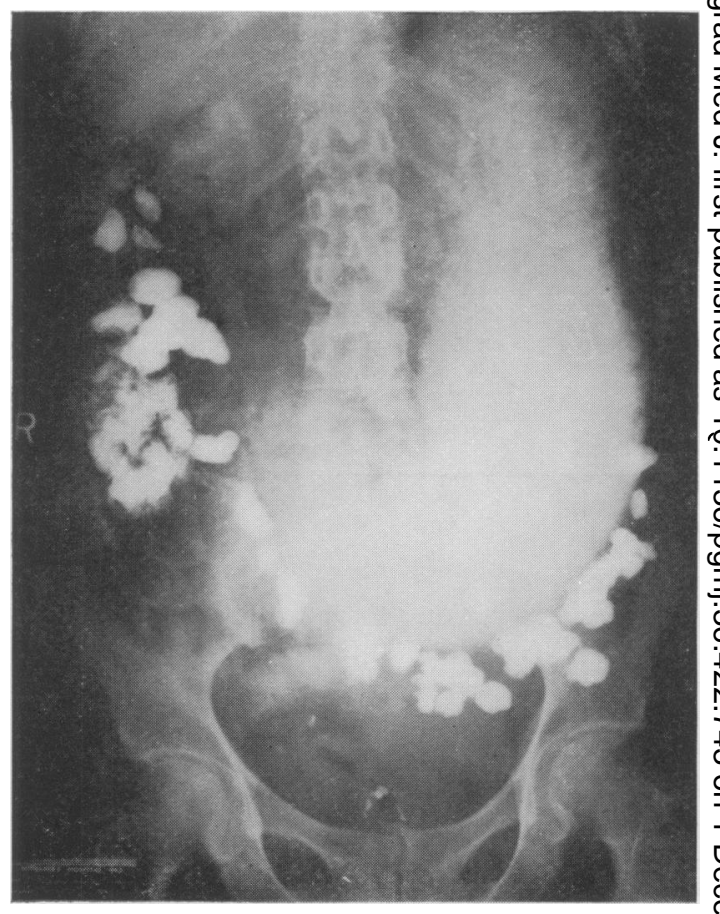

FIG. 2.-Further radiograph of the same patient after $\frac{3}{8}$ repeated gastric lavage. The stomach is smallęr $\mathrm{T}$ but is still outlined by retained barium.

and vomiting in a patient with peptic ulceratio may be attributed to food poisoning and this may lead to omission of further investigation. The combination of body fluid depletion, vomiting and a raised blood urea may suggest chronic $\frac{\otimes}{\square}$ renal disease, but the high specific gravity of $\varrho$ the urine and the increased plasma bicarbonate $\overrightarrow{\vec{O}}$ level in pyloric stenosis make distinction easy. 3 Rarely in the severely alkalotic patient the abdominal symptoms may be concealed by mental confusion or even coma. ${ }^{22}$ For this Hurst ${ }^{13}$ used음 the term 'coma dyspepticum', attributing it to Von Sakset.

The pre-operative diagnosis of the underlying lesion in a patient with pyloric stenosis is not of 3 paramount importance, but clinically a short history of dyspeptic symptoms before the onset of stenosis is suspicious of carcinoma. A mass is rarely palpable in the abdomen nor is it certain evidence of malignancy. Even radiology may be inconclusive.

\section{Metabolic Changes}

Many patients with pyloric stenosis suffer fromt the effects of loss of electrolytes and water pre- - ? senting in its most severe form as gastric tetany. 'This was first described in 1886 by $\mathrm{Kussmaul}^{+}$ and in the early part of this century the disorder 


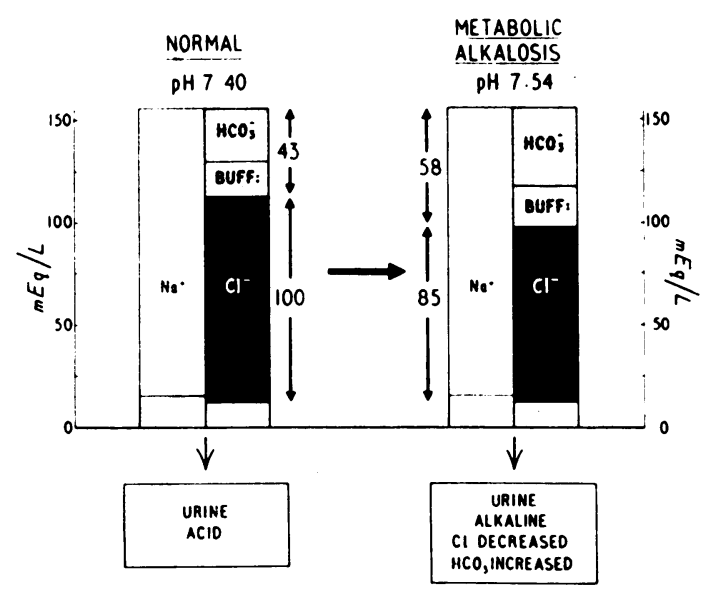

Fig. 3.-Typical changes in the extracellular electrolytes in a patient with pyloric stenosis. (From Le Quesne. ${ }^{15}$ )

was attributed to the secretion of toxins by the pylorus or obstructed stomach. McCallum and others in $1920^{16}$ demonstrated that the blood was abnormally alkaline with an associated increase in neuromuscular excitability, and attributed these changes to loss of acid and chlorides in the vomit. Gamble and Ross ${ }^{11}$ demonstrated, in dog experiments, that an accompanying loss of sodium ions caused the dehydration. They showed that water or ammonium chloride solutions were ineffective therapy but that saline was curative. Subsequent workers $4,6,14,17,19$ have demonstrated marked depletion of potassium in gastric alkalosis.

The metabolic disturbance of pyloric stenosis is caused by the loss of large amounts of acid gastric contents, probably as much as four litres per day in the worst cases. The magnitude of the losses of the important electrolytes can be seen from their mean concentrations in the gastric aspirate (Table I). The net effects of these losses

TABLE I

Electrolyte Concentrations in the Gastric Content of Patients with Pyloric Stenosis, at the Time of AdMission to Hospital

\begin{tabular}{llll|c|c}
\hline & & & & $\begin{array}{c}\text { Benign } \\
\text { Ulceration }\end{array}$ & Carcinoma \\
\hline Sodium &. & $\ldots$ &. & 50 & 55 \\
Potassium & $\ldots$ & $\ldots$ &. & I I & II \\
Chloride & $\ldots$ & $\ldots$ & $\ldots$ & I I7.5 & 5 I \\
\hline
\end{tabular}

(All values as $\mathrm{mEq} . /$ litre.)

are characteristic; the extracellular fluid and circulating blood volumes are reduced, the plasma chloride concentration is lowered with a corresponding increase in the plasma bicarbonate level

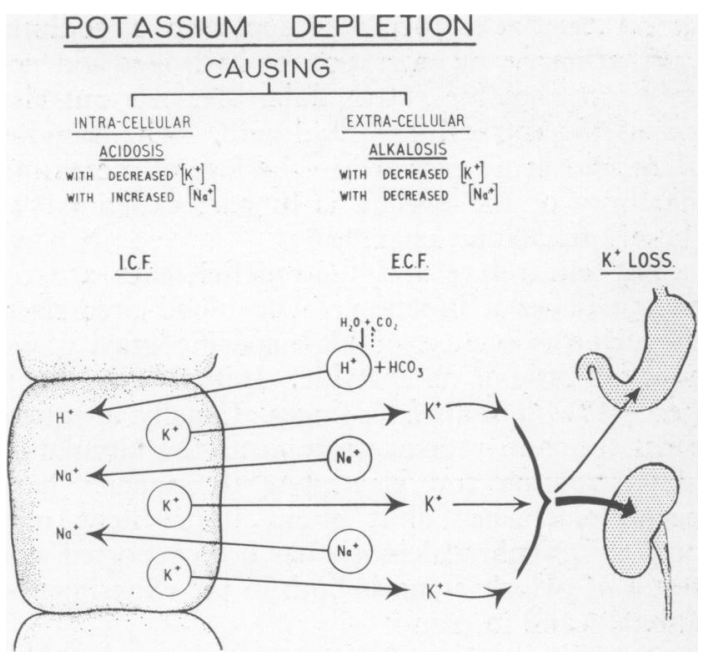

FIG. 4.-The intracellular-extracellular ionic shifts and their effects in potassium depletion. (From Le Quesne. ${ }^{15}$ )

and the plasma is more alkaline, i.e. a state of hypochloraemic alkalosis (Fig. 3).

The kidney normally excretes an acid urine, but as a result of the extracellular alkalosis in pyloric stenosis the urine formed is alkaline in reaction. The sustained excretion of an alkaline urine represents a considerable departure from normal, entailing the loss of large quantities of sodium or potassium in place of hydrogen ion, thus conserving the latter and limiting the degree of extracellular alkalosis. By this increased urinary excretion of sodium and potassium the kidneys convert a gastric loss of hydrochloric acid into a total body loss of sodium and potassium chloride.

In the early stages of pyloric stenosis the gastric and urinary losses of sodium lead to considerable depletion. Gamble and Ross ${ }^{11}$ have described sodium as the skeleton of the extracellular fluid and its depletion is accompanied by a proportionate loss of water thus reducing the extracellular volume. This process is limited by marked reduction in the sodium content of the urine, but potassium excretion continues undiminished despite a falling plasma level. It is the loss by this route which is largely responsible for potassium depletion. ${ }^{21}$

It has long been known that the urine may become acid in the late stages of extracellular alkalosis. ${ }^{7,13}$ This change in urinary reaction is connected with internal rearrangements of the electrolytes between the intracellular and extracellular fluids due to potassium depletion. ${ }^{8,}, \mathbf{9}, 20$ Potassium is the principal cation of the intracellular fluid and, when it is lost from the body, sodium and hydrogen ions from the extracellular fluid enter the cells to replace it (Fig. 4). This 
aggravates the extracellular depletion of sodium. Furthermore, the migration of hydrogen ion not only increases the extracellular alkalosis but also makes the intracellular fluid acid. The paradox of an acid urine excreted in the face of increasing alkalinity of the plasma is in part explained by these intracellular changes. ${ }^{2}$

The electrolyte and fluid deficiencies are reflected in renal function. The blood urea rises, the urine is scanty, of high specific gravity and contains little or no chloride. Initially alkaline, it becomes acid in the later stages. Usually, adequate renal function returns as soon as the circulating blood volume and electrolyte deficiencies have been replenished, but slight impairment may persist. $^{5}$ Nephrocalcinosis has been reported as a result of pyloric stenosis both in the experimental animal $^{18}$ and in man. ${ }^{7}$

\section{Treatment}

The aims of initial treatment of patients with pyloric stenosis are threefold: to promote healing of the causative ulcer and alleviate pain, to relieve the effects on the stomach of long-standing obstruction, and by replenishing the fluid and electrolyte deficiencies to correct the metabolic disturbance. The definitive treatment should be surgical. Bed rest and, possibly, antacids with sedatives promote healing of the ulcer and regression of the surrounding inflammatory reaction, thus helping to overcome the obstruction and making subsequent operation easier. Atropine or other anti-cholinergic drugs should not be given as any effects they may have in opening the pylorus is offset by their depressant effect on gastric motility.

Local treatment of the stomach consists of emptying it and preventing the accumulation of stagnant contents. A large bore oesophageal tube may be necessary for the initial lavage. Subsequently, a small bore tube of the Ryle's type may be used, but it is important to remember that anything given by mouth may have to be withdrawn through the tube later. In the milder case a traditional ulcer diet may be given, but the stomach should be emptied each evening. In more severe cases with persistently large residues the tube may be left in place and a fortified milk feed given through it during nine hours out of each twelve, the stomach being aspirated three hours after each feed ends. Pain is rapidly relieved, the pylorus opens up (as shown by a steadily decreasing aspirate), and the patient comes to operation with a clean stomach that can be handled and sutured with safety.

In all but the mildest cases water and electrolytes should be given parenterally and an initial assessment of the patient's needs can be made
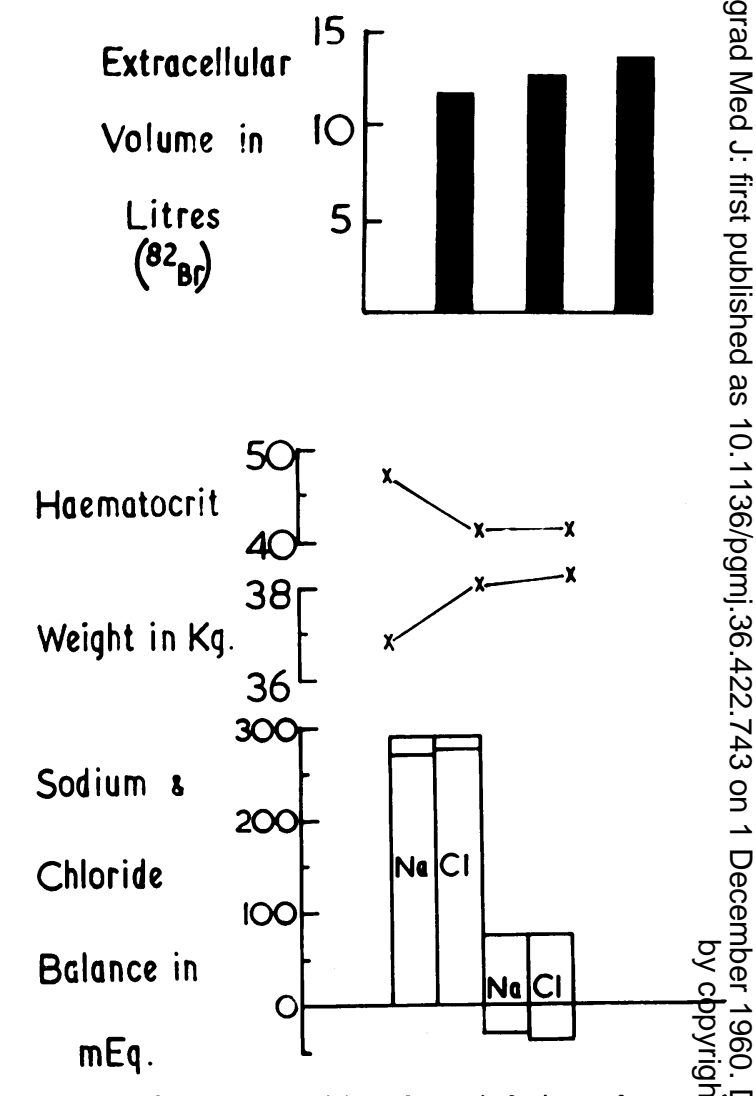

FIG. 5.-Changes resulting from infusion of nornatal saline in a patient with pyloric stenosis due to carcinoma. In the first I2-hour period sodium and chloride are retained equally. In the second period no further retention occurs, showing thato approximate equilibrium has been achieved. The $\mathbb{Q}$ extracellular volume rises, as demonstrated by $\vec{F}$ direct measurement using ${ }^{82} \mathrm{Br}$., and indirectly응 by the fall in haematocrit level and the gain in weight.

without laboratory tests, although these make management of a severe case much simpler. The severity of the vomiting and clinical signs of salto. and water depletion or latent tetany will give an $\frac{\mathrm{O}}{3}$ index of the losses that have occurred. The simpler tests include the volume, specific gravity, chloride content and reaction to litmus of the urine. If there is an appreciable electrolyte deficiency an acid urine indicates severe potassium $\mathrm{N}_{\sigma}$ depletion. The blood urea, bicarbonate (or alkali ${ }_{i} \mathrm{~N}$ reserve) and haemoglobin are the most useful laboratory investigations. The plasma electrolyte ${ }^{\omega}$ levels are helpful in the more complicated cases.? Low plasma levels of sodium or potassium indicate a body deficit of these ions, but normal levels may be found despite significant degrees of ${ }^{+}$ depletion. A raised blood urea is probably the 
best indication for saline therapy and a raised plasma bicarbonate for potassium therapy.

In the simple case where there is little disturbance of acid-base equilibrium the administration of normal saline will increase the extracellular volume with clinical improvement, gain in weight, the establishment of an adequate urinary flow and a fall in the haematocrit reading (Fig. 5). Where considerable disturbance of acid-base balance has already occurred with signs of peripheral circulatory failure the overriding need is for fluid and salt. Although over-hydration is a danger, especially in cardiac disease, insufficient infusion is a commoner error. Deficits of 500-600 mEq. each of sodium and chloride representing a need of 4 litres of normal saline for replenishment are commonly encountered and cases occur with total body deficits of sodium and chloride in excess of $1,500 \mathrm{mEq}$. (ro litres of normal saline).

In estimating the deficit the following rules are helpful: if clinical signs of depletion are minimal but chloride is absent from the urine, 2 litres of saline will be needed; if obvious clinical signs are present the loss equals $6 \%$ of the body weight (e.g. 4 litres in a 70-kg. man); if peripheral circulatory failure is present it represents a loss of at least 6 litres. In planning the intravenous treatment it is best to replace half the estimated deficit in the first 12 hours and then review the position, aiming at complete replenishment in 48 hours. The losses by aspiration over each 12 -hour period must be measured and an equivalent volume of normal saline should be added to the intake for the next period. These amounts are additional to the basic requirements of a patient receiving little flid by mouth.

In pyloric stenosis of any severity potassium depletion is invariably present and potassium chlorice should be given orally in all patients. In the inore severely depleted patient excreting an acid urine despite severe extracellular alkalosis, it may be advisable to break the general rule and administer potassium parenterally before there is an adequate urinary flow. The prolonged administration of saline alone in such a patient may result in a dangerous lowering of the concentration of potassium in the extracellular space both by dilution and by increasing the renal excretion of potassium. ${ }^{10,17}$ Furthermore, saline administration, although it may occasionally make the urine alkaline in reaction, only partly corrects the alkalosis. ${ }^{6,8,14,23}$ Correction of potassium depletion with potassium chloride results in displacement of sodium and hydrogen ions from the intracellular fluid, thus helping to correct both the alkalosis and sodium depletion of the extracellular fluid (Fig. 6). Parenteral potassium may

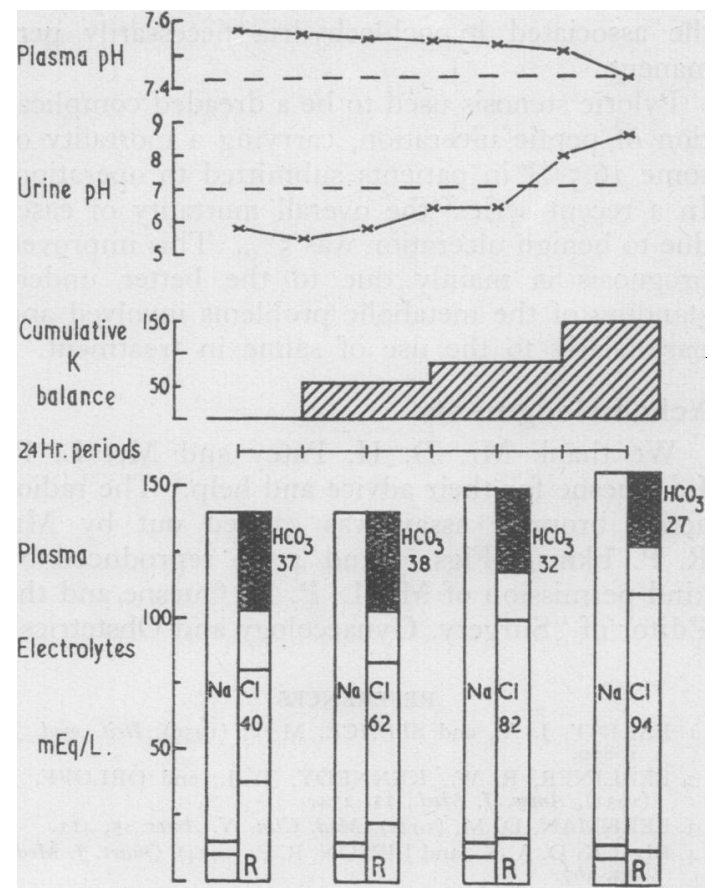

Fig. 6.-Plasma and urinary changes during correction of the water and electrolyte deficit in a patient $\bar{Z}$ with pyloric stenosis due to carcinoma. Saline $\mathbb{D}$ was administered and sodium retained throughout the period of study. The plasma electrolyte concentrations were restored almost to normal before the urine became alkaline.

be administered conveniently by adding $40 \mathrm{ml}$. of $10 \%$ potassium chloride to each litre of intravenous fluid, giving a concentration of approximately $50 \mathrm{mEq}$. per litre. Not more than 2 litres of this should be given in 12 hours unless there is a dangerous degree of hypokalaemia. If tetany is present calcium gluconate can be given intravenously. Ammonium chloride is contraindicated as, apart from being inadequate replacement therapy for the multiple deficiencies, it has a harmful diuretic effect. Re-expansion of the extracellular space often unmasks anaemia in patients with pyloric stenosis and this should be corrected by blood transfusion before operation.

Once the metabolic defects of a severe case have been rectified and the stomach emptied operation should not be delayed. The procedure of choice is partial gastrectomy, but gastroenterostomy has a limited place in irremovable carcinoma of the stomach or in very ill patients. This operation has been advocated in the past for long-standing cases where gastritis due to gastric retention has reduced acid section to a low level. Such advanced cases are now rarely seen nor is 
the associated hypochlorhydria necessarily permanent.

Pyloric stenosis used to be a dreaded complication of peptic ulceration, carrying a mortality of some $16.5 \%$ in patients submitted to operation. In a recent series ${ }^{1}$ the overall mortality of cases due to benign ulceration was $5 \%$. This improved prognosis is mainly due to the better understanding of the metabolic problems involved and particularly to the use of saline in treatment.

\section{Acknowledgments}

We thank Mr. D. H. Patey and Mr. L. P. Le Quesne for their advice and help. The radioactive bromine assay was carried out by $\mathrm{Mr}$. R. P. Ekins. Figs. 3 and 4 are reproduced by kind permission of Mr. L. P. Le Quesne and the Editor of ' Surgery, Gynaecology and Obstetrics'.

\section{REFERENCES}

I. BALINT, J. A., and SPENCE, M. P. (1959), Brit. med. F. i, 890 .

2. BERLINER, R. W., KENNEDY, T. J., and ORLOFF, J. (195I), Amer. F. Med., II, 274

3. BERKMAN, D. M. (1921), Med. Clin. N. Amer., 5, 411 .

4. BLACK, D. A. K., and JEPSON, R. P. (1954), Quart. F. Med., 23,367
5. BURNETT, C. H., BURROWS, B. A., and COMMONS, R. R. (1950), f. clin. Invest., 29, Part I, 169.

6. BURNETT, C. H., BURROWS, B. A., COMMONS, R. R., and TOWERY, B. T. (1950), Ibid., 29, Part I, 175.

7. COOKE, A. M. (1933), Quart. F. Med., 2, 539.

8. COOKE, R. E., SEGAR, W. E., CHEEK, D. B., COVILLE, $\subseteq$ F. E., and DARROW, D. C. (I952), F. clin. Invest., 31, 798.

9. DARROW, D. C., SCHWARTZ, R., IANUCCI, J. F., and COVILLE, F. (1948), Ibid., 27, 198.

10. ELKINTON, J. R., and WINKLER, A. W. (1944), Ibid., 을 23, 93 .

II. GAMBLE, J. L., and ROSS, S. G. (1925), Ibid., I, 403.

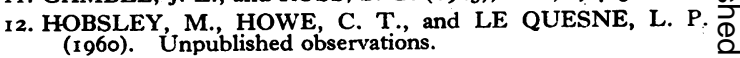

13. HOUGHTON, L. W., VENABLES, J. F., and LLOYD, N N. L. (1925), Guy's Hosp. Rep., 5, 147.

14. LANS, H. S., STEIN, I. F., and MEYER, K. A. (1952), $\overrightarrow{0}$ Ann. Surg., 135, 441.

15. LE QUESNE, L. P. (1960), Surg. Gynaec. Obstet., in press. $\overrightarrow{\vec{H}}$ 16. MCCALLUM, W. G., LINTZ, J., VERMILYE, H. N., LEGGETT, T. H., and BOAS, E. (1920), Bull. Fohns Hopk. O Hosp., 31, 1.

17. NELSON, R. M., FRIESEN, S. R., and KREMEN, A. J. (1950), Surgery, 27, 26.

18. PYRAH, L. N. (1949), Brit. F. Uiroi., 21, 27.

19. RITCHIE, J. B., and SMITH, A. N. (1959), Brit. f. Surg., 46, 625 .

20. SAUNDERS, S. J., IRVINE, R. O. H., CRAWFORD, M. A., ? and MILNE, M. D. (1960), Lancet, i, 468.

21. TARAIL, R., and ELKINTON, J. R. (1949), J. clin. Invest.; $\vec{\omega}$ 28, 99.

22. UNGLEY, H. G. (1948), Lancet, ii, 218.

23. VAN SLYKE, K. K., and EVANS, E. I. (1947), Ann. Surg., 126, 545 .

\section{RENAL DISEASE}

(Postgraduate Medical Journal, November 1959)

Price 6s. 6d. post free

RECENT DEVELOPMENTS IN THE STUDY OF THE KIDNEY

A. A. G. Lewis, B.Sc., M.D., M.R.C.P.

RENAL BIOPSY AND

GLOMERULONEPHRITIS

J. H. Ross, M.D., M.R.C.P.

RECENT ADVANCES IN THE TREATMENT OF RENAL DISEASE

A. G. Spencer, M.D., M.R.C.P.

\section{AORTOGRAPHY}

I. H. Griffiths, F.R.C.S.

\section{HAEMODIALYSIS}

F. M. Parsons, B.Sc., M.B., Ch.B.

\section{DIURETICS}

H. G. Lloyd-Thomas, M.A., M.B., M.R.C.P.

\section{URINARY DIVERSION}

John Hopewell, F.R.C.S.

RENAL ARTERY STENOSIS

Kenneth Owen, M.S., F.R.C.S.

Published by

THE FELLOWSHIP OF POSTGRADUATE MEDICINE

9, Gt. James Street, W.C.1 